\title{
Discussion on Municipal Road Design Optimization based on BIM Technology
}

\author{
Yong Yang*
}

China Merchants Chongqing Communications Technology Research \& Design Institute Co., Ltd., Chongqing 400067, China

\begin{abstract}
In order to improve the implementability of municipal road design, the rational application of BIM Technology in the process of road design is a common method in current road engineering design units. The advantages of BIM Technology, such as visualization, simulation, coordination and optimization, are increasingly recognized by the industry. In this paper, the author draws on many years of practical experience to introduce the advantages of BIM Technology, as well as how to apply BIM Technology to optimize municipal road design work and to discuss some views, in the hopes of assisting in the further improvement of the level of municipal road constructions in China.
\end{abstract}

Keywords: BIM Technology; Municipal roads; Design and application; Value analysis

Publication date: May, 2021; Publication online: 31 May, 2021

*Corresponding author: Yong Yang, yangyong1@ cmhk.com

Yong Yang, master and senior engineer, who was born in Nanchong, Sichuan Province in 1990, works in road surveying, desig ning and consulting.

\section{Introduction}

Based on the rapid expansion of China's municipal road scale in recent years, the road engineering design concept has changed to a great extent, especially in some large area road network construction, bridge and tunnel comprehensive engineering, where the traditional design method has been unable to meet the increasing demand for project visualization. Recognizing the advancement of BIM Technology, its incorporation into the municipal road engineering design can not only reflect the advantages of visualization and simulation in the design, but also has a high implementation value in terms of reducing the construction period, improving the construction quality and lowering the investment cost. Scholars Wang Yasheng and Wang $\mathrm{Yu}^{[1]}$ discussed the implementation of BIM Technology in municipal site planning, road traffic optimization, underground pipeline layout, landscape and surrounding environment coordination, engineering quantity statistics and review, in the hopes to provide new design ideas for the municipal road projects. In addition, Gao Sheng ${ }^{[2]}$ has introduced appropriate improvement measures to make BIM Technology's implementation in municipal road engineering design more scientific and reasonable. In the following statements, the author discusses some perspectives on BIM Technology in the optimization design of municipal road, in order to enhance the design of municipal road engineering in China and create a trustworthy municipal engineering.

\section{BIM Technology Advantages}

\subsection{High degree of visualization}

The biggest implementation advantage of BIM Technology should be its high degree of visualization. In the designing stage, the relevant work can be completed intuitively based on threedimensional plans. At the same time, acknowledging the sophisticated modeling and rendering capabilities of BIM Technology, both the effect display of design outcomes and the construction simulation will be accessible. The rational implementation of BIM Technology in the design of the municipal road engineering can not only correct the design errors in time for the design 
unit, but also provide more rapid visualized and construction unit. In the past, when we carried out the design work of the municipal road engineering, all the design plans were presented in the form of plane paper drawings. Since these kind of design drawings are limited to plane expression, it's easy for the construction unit to have a poor interpretation, resulting in confusion during construction and even rework. The implementation of BIM Technology to the municipal road engineering design can connect all links naturally and achieve overall engineering design control by ensuring the accuracy of each design unit.

\subsection{High degree of simulation}

Considering BIM Technology is based on a software to achieve a function, it may be seamlessly integrated with modern digital analogue simulation systems. This method can not only make engineering design and simulation work more realistic, but it can also visually present the design structure, according to practice. For example, in the design of a downtown road section, the street surrounding signboards and traffic signal lights can be clearly displayed on the design drawings, ensuring that the entire simulation is achieved. The simulation effect on municipal road is shown in Figure 1.

\subsection{Strong optimization}

The implementation of BIM Technology can really optimize the overall process of the project. At the start of the design process, the main links of engineering design, construction and management

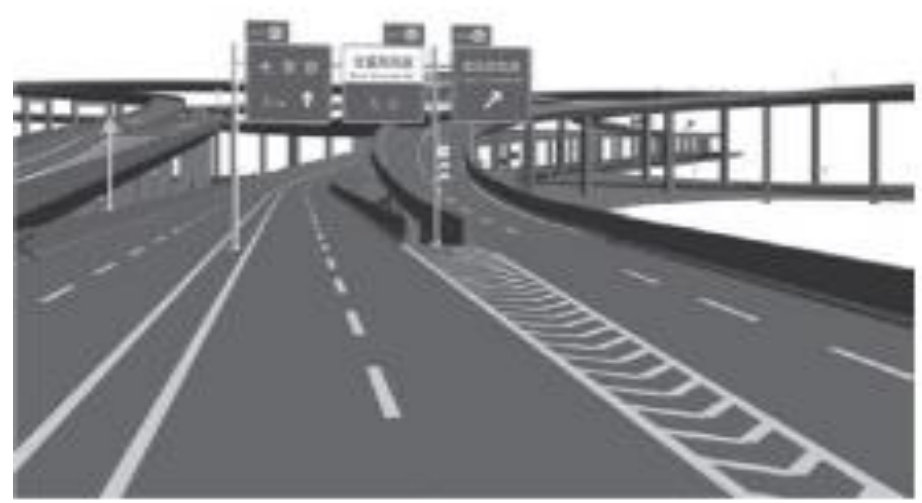

(a) Effect before simulation three-dimensional implementation plan for the can be optimized in real time. The traditional design plan can be difficult to create the appropriate construction plan, especially for the projects with large quantities and high technical content, but BIM Technology can be very competent, allowing the entire project to be perfectly displayed in the design drawings. The comparison of BIM Technology optimization plans is shown in Figure 2.

\subsection{High coordination}

For municipal road engineering, whether in the design or construction process, it requires multiple departments to clearly divide their responsibilities, coordinate and upgrade, in order to enhance completion of the overall work ${ }^{[3]}$. However, there are differences in the starting point between the design and construction units which may easily lead to having differences in some details during the construction process, resulting in reducing the construction benefit and increasing the construction cost. Nevertheless, BIM Technology can solve the problem with its high coordination software which integrates information series design and construction. It can not only better simulate the entire engineering construction process, but also make Party $\mathrm{A}$ and the construction unit more aware of the entire construction process and identify potential problems in construction in time, ensuring the smooth progress of engineering construction, improving engineering quality and reducing construction cost and increasing enterprise economic efficiency.

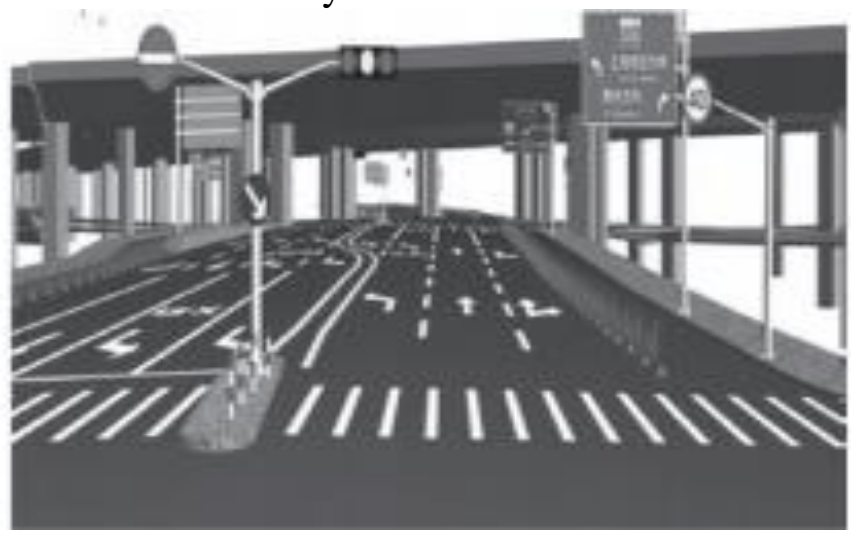

(b) Effect after simulation

Figure 1. Simulation effect on municipal road 
3 Discussion on Municipal Road Design Optimization Plan based on BIM Technology

3.1 Analysis of information model software for synchronization management

In essence, BIM Technology is a comprehensive information model software for design and construction that integrates all types of closely related data information. As a result, BIM Technology has a significant advantage in terms of information synchronization management, as it can make engineering physical and functional characteristics available in digital form. In practical implementation, when a decision needs to be made, the data information in the software can be directly extracted to provide important data reference for engineering decision-making. For example, in the process of laying out municipal pipelines, a BIM software can integrate all kinds of pipe network engineering information and clearly achieve the information management of municipal road construction. In addition, the municipal road operation and maintenance software in BIM integrates BIM, Internet of Things and GIS technology, allowing the municipal road engineering management work orderly.

\subsection{Realization of geographic data informatization}

The display of geographic information is enhanced using BIM technology, whereby its threedimensional display will be more vibrant than the standard two-dimensional geographic display and vertical display. Furthermore, different colors are utilized to indicate different layers so that soil information, soil thickness, and continuity can be viewed from various perspectives ${ }^{[4]}$. At the same time, the BIM Technology can integrate all the parameters of each soil layer. thus, designers no longer have to choose engineering parameters between geographic profiles, drawings, and tables when carrying out design work, which greatly improves the work efficiency.

\subsection{Applying BIM Technology to route design}

The most important part of the municipal road route design is the determination of the route center line, which contains a variety of control elements in the design process. When designing urban roads, BIM Technology is used to simulate the road center line in urban road designs on the basis of conforming to the control elements, to find out the possible problems, adjust them in time and formulate the optimization plan. Through the application of BIM Technology, the design of the road route can be expressed as a three-dimensional model, which can avoid repeated modification, effectively improve the design level of the road and promote the Chinese urban road design to achieve more accurate outcome.

\subsection{Automatic calculation of quantities}

In the traditional two-dimensional design process, CAD engineering drawing can only store the geometric information such as points, lines and surfaces of the project, so the calculation of all information depends on manual work, which is not only low accuracy, but also time-consuming and laborious. BIM Technology can not only display the pavement, foundation, curb and other structures of the road, but also allow designers to use the data integrated by the software to quickly calculate the design quantities. The quantities calculated by BIM software can avoid human errors and make the calculation results more accurate as well as can be directly submitted to the cost department for calculation. As a result, the construction links are gradually refined as the refinement degree of BIM Technology improves, and project cost information becomes more transparent and accurate, whereby saving a lot of labor costs.

\subsection{Visual disclosure}

Visual disclosure can make the technical personnel of the construction unit quickly understand the design intention of each field of the project. At the same time, since the BIM software contains all kinds of geometric and auxiliary information, the construction unit can easily investigate the relevant data to ensure the consistency between the project completion results and the design, as well as it can greatly avoid the rework and waste in the construction process. 


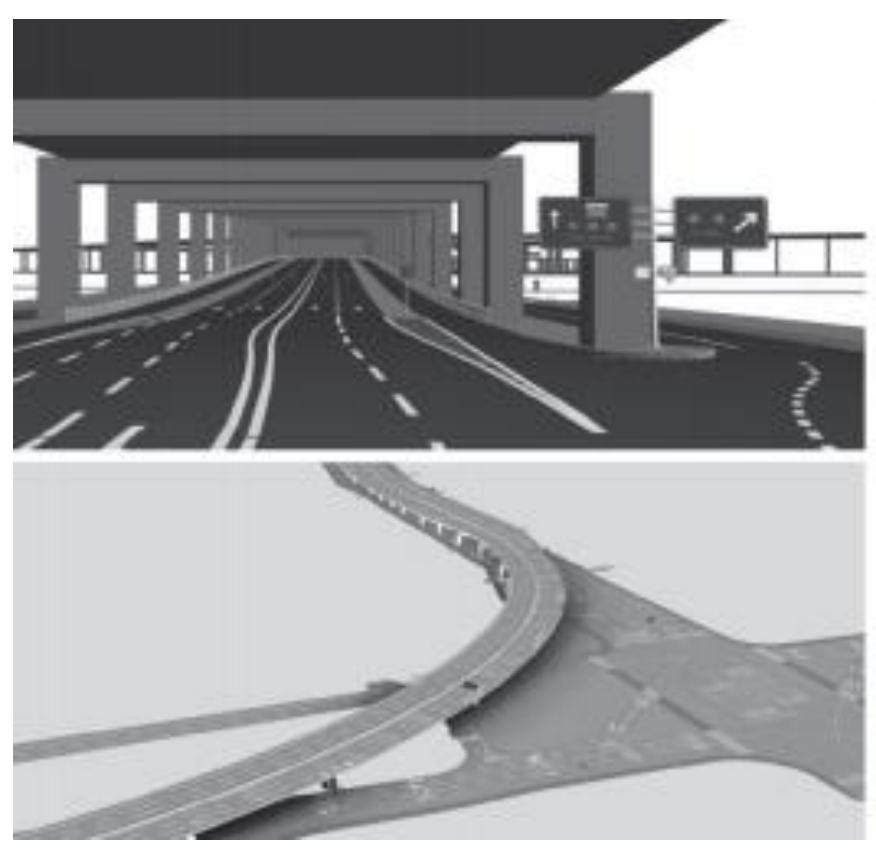

(a) Effect before optimization

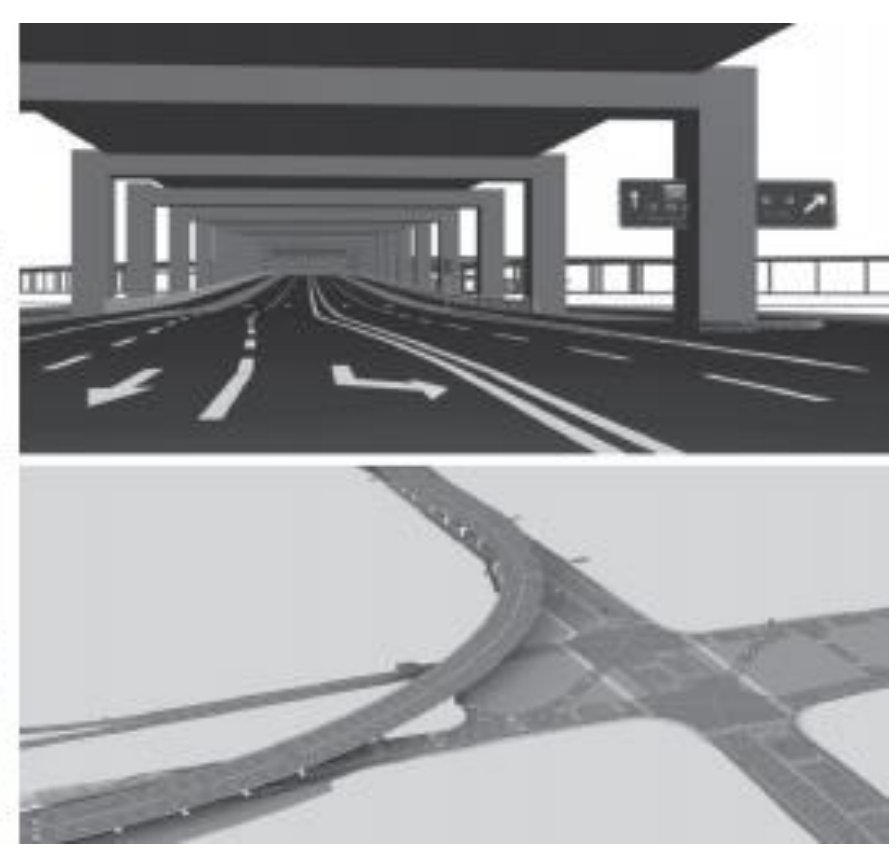

(b) Effect after optimization

Figure 2. Comparison of BIM Technology optimization plans

\section{Conclusion}

Firstly, this paper explores the implementation advantages of BIM Technology. Then, it discusses the municipal road design optimization plan based on BIM Technology. The analysis shows that the implementation of BIM Technology in urban road design can effectively replace the traditional twodimensional design. This will greatly improve the quality of project design, make the design of urban road more scientific and reasonable, as well as have a positive significance for optimizing urban road designs. Hopefully this paper can provide theoretical references for BIM Technology in the municipal road design, which will comprehensively improve the overall quality of the project as well as bring higher economic benefits.

\section{Disclosure statement}

The author declares no conflict of interest.

\section{References}

[1] Wang, Y.S., Wang(2021), Y. Optimization of Municipal Road Design based on BIM Technology[J]. Housing and real estate,(6): 25.

[2]Gao, S(2020). Municipal Road Optimization Design Strategy based on BIM Technology[J]. Sichuan building materials,(6): 10 .

[3]Zhang, X.H(2019). Application of BIM Technology in Municipal Road Design Optimization[J]. Intelligent City,(11): 14.

[4]Zhao, X.G(2017). Municipal Road Design Optimization based on BIM Technology[J]. Building materials and decoration,(12): 08.

[5]Zhang. Y(2009). Research on BIM based Construction Engineering Information Integration and Management[D]. Tsinghua University.

[6]Chen Y, Dai HJ, Liu J, et al(2008). Framework of Building Information Model (BIM) in Project Management Information System[J]. Construction technology,37(2): 5-8.

[7]Eastman, C., Teicholz, P., Sacks, R., et al(2008). BIM Handbook[M]. John Wiley \& Sons.

[8]Time to Start Thinking About BuildingInformation Modeling, Design Firm Management \& Administration Report; May 2004:4(5). 